\title{
Tuning-Rules for Fuzzy Controllers
}

\author{
Jantzen, Jan
}

Published in:

Proceedings of the IEEE International Workshop on Intelligent Motion Control

Publication date:

1990

Document Version

Publisher's PDF, also known as Version of record

Link back to DTU Orbit

Citation (APA):

Jantzen, J. (1990). Tuning-Rules for Fuzzy Controllers. In Proceedings of the IEEE International Workshop on Intelligent Motion Control (Vol. Volume 1, pp. 83-86). IEEE.

\section{General rights}

Copyright and moral rights for the publications made accessible in the public portal are retained by the authors and/or other copyright owners and it is a condition of accessing publications that users recognise and abide by the legal requirements associated with these rights.

- Users may download and print one copy of any publication from the public portal for the purpose of private study or research.

- You may not further distribute the material or use it for any profit-making activity or commercial gain

- You may freely distribute the URL identifying the publication in the public portal

If you believe that this document breaches copyright please contact us providing details, and we will remove access to the work immediately and investigate your claim. 


\title{
TUNING-RUIES FOR FUZZY CONTROLLERS
}

\author{
Jan Jantzen \\ Technical University of Denmark, Electric Power \\ Engineering Department, DK-2800 Lyngby, DENMARK. \\ e-mail: STARDUST at NEUVM1
}

\begin{abstract}
A theoretical study has shown that a fuzzy controller for a single-input-single-output process can be tuned in four intuitive steps, much like classical PID (proportionalintegral-derivative) controllers. A fuzzy lookup table controller becomes a PID controller if the lookup table is replaced by a summation. The relationships between the fuzzy gain factors and the PID tuning parameters are simple mathematical ratios and products. The results were applied to fuzzy controllers in simulation and on a laboratory water tank rig. Experiments show significant time-savings during tuning.
\end{abstract}

\section{INTRODUCTION}

In a local graduate course on fuzzy control, the students used to spend an hour or more tuning a fuzzy controller. By contrast, it takes $10-15$ minutes to tune a classical PID (proportional-integral-derivative) controller. The students mostly used trial and error for the fuzzy controller, because good, reliable tuning-rules are hard to find. The controlled object is a water tank rig in the laboratory. The objective is to adjust the water level after a step in the setpoint as fast as possible, with the smallest overshoot, and avoiding steadystate offset.

A study was then carried out in order to find an easy and fast way to tune a fuzzy controller for a single-input-singleoutput process.

The result is a set of tuning-rules (see the section 'Tuning-rule transfer'). Computer simulations of the water tank rig demonstrate, that the tuning progresses much like in the PID case (see Fig 3). Mathematical relationships link the tuning parameters of the fuzzy and PID controllers (see Table I and appendix).

The fuzzy controllers in question are table-based [4]. Referring to Fig.1, they use setpoint error, E, and change in error, CE, for input. The controller output is usually an incremental 'change in output', $\mathrm{CO}$, which is then integrated. Alternatively, the controller output can be the control signal, $O$, directly. These two controller configurations will be referred to as the 'CO-controller' and the 'O-controller'.

The gain factors - often named GE, GCE, GCO (GO for the O-controller) -- must be tuned to get the best transient response, and they are thus central to the study.

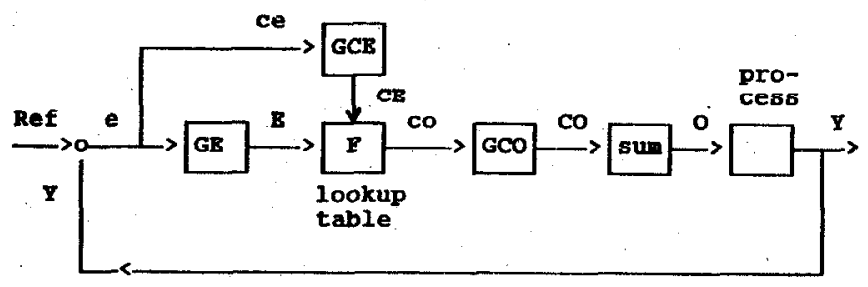

F1g. 1. Tuzzy co-controller
The inputs, $E$ and $C E$, are clipped and quantized to fit on to discrete universes on the two axes of the table. The choice of resolution is the designer's choice between sensitivity and computing time; 13 integer points centered around zero has been used as a standard universe by several researchers, [4] [8]. The numbers in the table result from a fuzzy inference, [9] involving several linguistic statements like: 'IF $E$ is Largepositive and $\mathrm{CE}$ is Largepositive THEN $\mathrm{CO}$ is Largenegative', [2]; the Largepositive and Largenegative are fuzzy sets defined on the standard 13 point universe.

Originally, the error axis of the table had a double zero, [4], due to a user-friendly definition of $E$ and $C E$. Yamazaki, [8] got rid of the double zero, by redefining $E$ to be a function of Ref - Y, and CE a function of $e(n)-e(n-1)$, like common practice. By this definition, the lookup table acts as a discrete phase plane.

\section{Tuning a fuzzy controller}

The literature on tuning-rules is rather sparse; the following is a summary.

It is common to view the gain factors as scaling factors, [3], [4], [8]. Thus the role of GE and GCE is to map the variation of $e$ and ce onto the standard universe to make the best use of the lookup table. The role of GCO (GO) is to keep the control signal within its operating limits. This results in the tuning-rules:

$$
\begin{aligned}
& \text { - keep abs (GE* Elarge) equal to } 6 \\
& \text { - keep abs (GCE* CElarge) equal to } 6 \\
& \text { - keep abs (GCO* COlarge) equal to } \\
& \text { the operating limits } \\
& \text { - keep abs (GO * Olarge) equal to the } \\
& \text { operating limit }
\end{aligned}
$$

where 'abs' means absolute value.

A fuzzy controller typically allows the process to wander a bit around the steady state (limit cycles). This is due to the discrete nature of the controller. It can be avoided to an extent by making the controller more sensitive to deviations from the setpoint, i.e. increasing GE. If the admissible steady state error is Epsilon, then

- keep abs (GE * Epsilon) less than or equal to 0.5

Thus E will jump to a neighbouring cell, if the error is larger than Epsilon, [3]. On the other hand, GE can get too large and make the system unstable. Pedrycz has found that

- for increasing GE, the response is faster with larger overshoots and significant oscillations;

- changing GCE hardly influences the rise-time and the peak-time, [5]. 
Some authors have found that the ratio $\mathrm{GCE} / \mathrm{GE}$ is important.

It is generally believed that the $C O$ controller is equivalent to the PI-controller, [4, p 1 187], [6], or at least 'superficially' similar, [8, p 190]:

However, tuning still remains an open problem: it is not clear how $\mathrm{GE}, \mathrm{GCE}, \mathrm{GCO}(\mathrm{GO})$, and the sampling time affect overshoot, rise time and steady state error -- in contrast with the PID controller.

\section{Tuning-rule transfer}

The central finding of the study is the following: if we omit the clipping and quantization of $E$ and $C E$, and replace the lookup table in Fig. 1 by a simple summation point, then we get a pure PI controller. This can be shown by block-diagram manipulations, or mathematically (see Appendix for details).

In case of an O-controller, the same trick would turn that into a pure PD controller. To get a fuzzy PID controller, the designer can include a third term, integral error $I E$, in the O-configuration (see Appendix).

A discrete PID controller can be written

$$
\mathrm{O}(\mathrm{n})=\mathrm{Kp} *\left[\mathrm{e}(\mathrm{n})+(1 / \mathrm{Ti}) * \Sigma \mathrm{ej}^{* T s}+\mathrm{Td} *(\mathrm{e}(\mathrm{n})-\mathrm{e}(\mathrm{n}-1)) / \mathrm{Ts}\right]
$$

where $O$ is the controller output, index $n$ is the time instant, $\mathrm{Kp}$ is the proportional gain, and $\mathrm{e}$ is the error. The error $\mathrm{e}$ equals Ref - Y (cf. Fig. 1). The Ti, Td and Ts are integral, derivative and sampling time respectively. Table I below holds the resulting relationships between the gains of the PID and fuzzy controllers. The sampling time Ts appears along with $\mathrm{GCE}$ in the formulas. It would disappear if $\mathrm{e}(\mathrm{n})-\mathrm{e}(\mathrm{n}-1)$ were divided by $\mathrm{Ts}$, in accordance with usual practice. Notice that there is a degree of freedom in the fuzzy controllers: there is always one more gain factor than in the PID case.

There is an empirical PID tuning approach, widely used, which is suitable for a transfer to fuzzy controllers, [7], [Foxboro in 1]:

1. Remove all reset ( $1 / \mathrm{Ti}=0)$ and derivative action $(\mathrm{Td}=0)$ and tune the proportional mode $(\mathrm{Kp})$ to give the desired response characteristics; ignoring any steady state offset.

2. Increase the proportional gain $(\mathrm{Kp})$, and attempt to restore the response characteristics by adjusting the derivative time (Td): Repeat until the proportional gain $(\mathrm{K} p)$ is as large as possible.

3. Adjust the reset time (Ti) to remove the offset.

Using the formulas in Table $I$, it is possible to make similar tuning-rules for the fuzzy controllers:

1. Remove all integral action, i.e keep GE very small and GCE large (CO-controller) or GIE = 0 (fuzzy PID). Remove all derivative action, i.e. put $G C E=0$ (O-controller and fuzzy PID). Tune the proportional gain, cf. the $\mathrm{Kp}$ column in the table, to give the desired response characteristics (overshoot), ignoring steady state offset.

2. Increase the proportional gain (cf. the Kp column), and attempt to restore the response characteristics by adjusting the derivative time (cf the Td column). Repeat until the proportional gain is as large as possible.

3. Adjust the reset time (cf. the $\mathrm{Ti}$ column) to remove the offset:

4. Use the extra degree of freedom to place the gains according to the section 'Tuning a fuzzy controller'.
TABLE I. Relationships between fuzzy and PID gains

\begin{tabular}{lcccc}
\hline Fuzzy & Kp & Td & $1 / T \mathbf{~}$ \\
\hline & & & & \\
CO-controller & GCE*GCO & 0 & GE/(GCE*Ts) \\
O-controller & GE*GO & $($ GCE*Ts/GE) & 0 \\
Fuzzy PID & GE*GO & GCE/GE & GIE/GE
\end{tabular}

Computer simulations will serve to evaluate and illustrate the usefulness of the tuning-rules next.

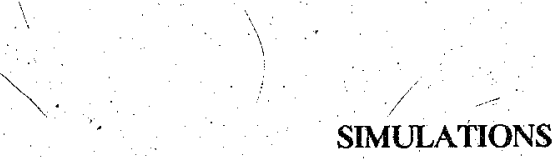

The simulated object is a laboratory water tank rig. The objective is to adjust the water level after a step in the setpoint $A$ pump feeds the water tank and a load pump takes water out again, see Fig. 2. The block-diagram was turned into the discrete state-space form using the basic MATLAB computer package. The PID and fuzzy controllers have been coded in MATLAB m-files, and the simulation progresses iteratively.

The first series of experiments (Fig. 3, top row and bottom left) uses a CO-controller with a linear lookup table. That is, each element in the table is the sum of the numbers on the axes; thus the largest table element is 12 . The step responses in Fig. 3 (top left), are indeed similar to proportional control with increasing proportional gain. The gain GCO is useful in adjusting the proportional gain; because it does not affect the integral gain, cf. Table I. The steady-state error decreases with increasing GCO, because the proportional gain increases (cf: Table I). The system oscillates perhaps a little more than genuine P control. In Fig. 3 top right, the integral gain increases with increasing GE (cf. Table I). The steady-state error disappears and the overshoot increases, as in a PI controller. The size of GE should preferably be larger than 6. Otherwise, the universe, and the lookup table, will not be used to the full extent when there is a unit step in the setpoint.

Fig. 3, bottom left, compares the tuned CO-controfler with the equivalent (in the sense of Table I) genuine PID. The fuzzy controller has less overshoot and longer rise time. This 'sluggishness' is characteristic of the fuzzy controller, and often referred to as robustness. It is interesting to note, though, that the explanation lies with the clipping and quantization in the fuzzy controller, being the only difference between the two controllers in the figure.

The O-controller and the fuzzy PID controller are easier to tune than the CO-controller, and similar graphs can be produced for them.

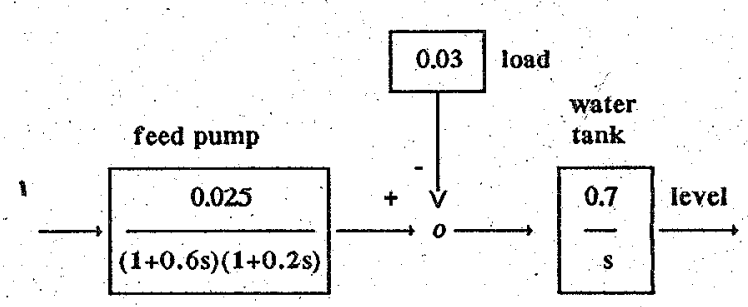

Fig. 2. Laboratory water model. 

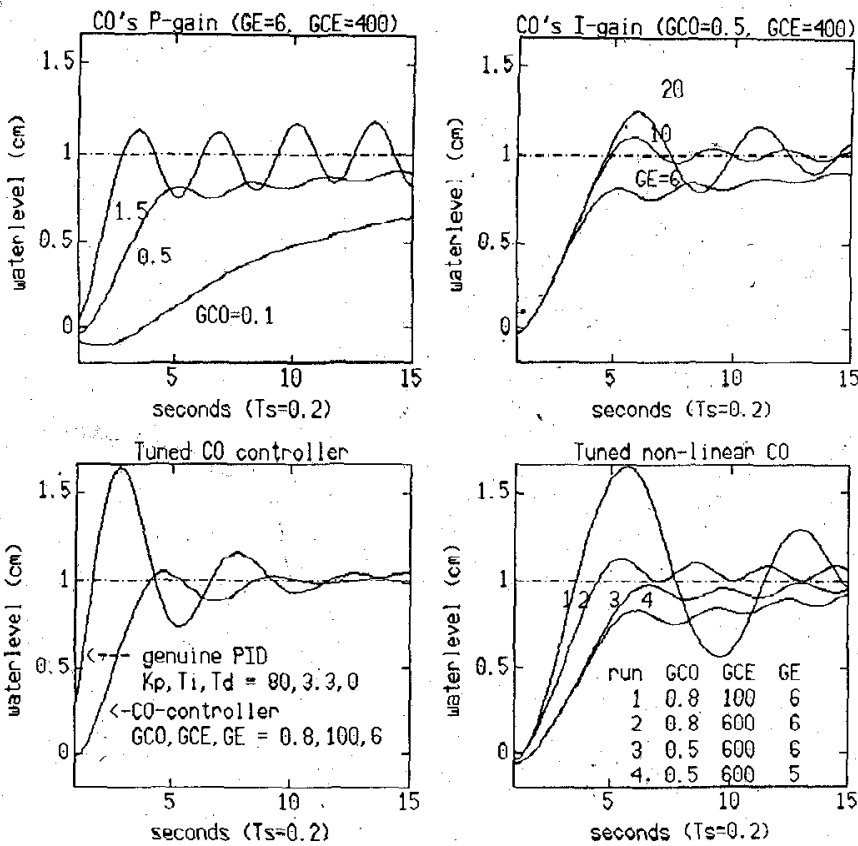

Fig. 3. Successive tuning. Top left: CO-controller with linear look-up table, tuning the proportional mode. Top right: CO-controller with linear lookup table, tuning the integral mode. Bottom left: CO-controller with linear table and the equivalent PID controller. Bottom right: $\mathrm{CO}$-controller with non-linear lookup table.

TABLE II.

Non-linear lookup table used in Fig. 3, bottom right.

CHANGE IN ERROR

$$
\begin{array}{lllllllllllll}
-6 & -5 & -4 & -3 & -2 & 1 & 0 & 1 & 2 & 3 & 4 & 5 & 6
\end{array}
$$

\begin{tabular}{rrrrrrrrrrrrrrr}
\hline & -6 & -7 & -7 & -7 & -7 & -7 & -7 & -7 & -7 & -4 & -4 & -4 & -6 & 0 \\
& -5 & -6 & -6 & -6 & -6 & -6 & -6 & -6 & -5 & -5 & -4 & -4 & -6 & 0 \\
& -4 & -6 & -6 & -6 & -6 & -6 & -6 & -6 & -4 & -4 & -4 & -4 & -6 & 0 \\
$\mathbf{E}$ & -3 & -5 & -5 & -4 & -4 & -4 & -4 & -4 & -4 & -4 & -4 & -4 & -5 & 0 \\
$\mathbf{R}$ & -2 & -4 & -4 & -4 & -4 & -4 & -4 & -4 & -4 & -4 & -4 & -4 & 4 & 4 \\
$\mathbf{R}$ & -1 & -4 & -4 & -4 & -4 & -4 & -4 & -4 & 2 & 2 & 3 & 4 & 4 & 4 \\
$\mathbf{O}$ & 0 & -4 & -4 & -4 & -3 & -1 & -1 & 0 & 1 & 1 & 3 & 4 & 4 & 4 \\
$\mathbf{R}$ & 1 & -4 & -4 & -4 & -3 & -1 & -1 & 4 & 4 & 4 & 4 & 4 & 4 & 4 \\
& 2 & -4 & -4 & 4 & 4 & 4 & 4 & 4 & 4 & 4 & 4 & 4 & 4 & 4 \\
& 3 & 0 & 6 & 4 & 4 & 4 & 4 & 4 & 4 & 4 & 4 & 4 & 6 & 6 \\
& 4 & 0 & 6 & 4 & 4 & 4 & 4 & 6 & 6 & 6 & 6 & 6 & 6 & 6 \\
& 5 & 0 & 6 & 4 & 4 & 6 & 6 & 7 & 7 & 7 & 7 & 7 & 7 & 7 \\
& 6 & 0 & 4 & 4 & 4 & 7 & 7 & 7 & 7 & 7 & 7 & 7 & 7 & 7
\end{tabular}

The second series of experiments (Fig. 3, bottom right) uses a non-linear lookup table for the CO-controller, Table II. The table is Mamdani's table, [4], but modified according to the modified definitions of $E$ and $C E$. Even this controller shows proportional and integral behaviour. The performance seems worse, but that is not surprising, since the table was designed for another process.

\section{CONCLUSION}

The new tuning-rules have in fact cut the time the students need to tune the laboratory water tank rig, from one hour to 10 - 15 minutes. The CO-controller is a little harder to tune than the O-controller and the fuzzy PID controller proposed in Appendix, because its integral action cannot be removed completely. In that respect, it is easier to use the fuzzy PID configuration; here the integral and derivative gains can be put to zero independently and at will.

A future study will try and transfer other PID tuning-rules, for example the Ziegler-Nichols recommendations, using the established link between fuzzy and PID controllers.

\section{LITERATURE}

[1] Astrom, K.J.: "Reglerteknik; en elementaer introduktion". (Automatic Control:' an Elementary Introduction). Lund's Technical University: Institutionen for Reglerteknik, 1982, 5.1-5.46 (chap. 5: "PID reglering").

[2] Holmblad, L.P \& J.-J. Ostergard: "Control of a Cement Kiln by Fuzzy Logic." Fuzzy Inf. Decision Processes. $1982,389-399$.

[3] Jespersen, T.: "Self-organizing Fuzzy Logic Control". Technical University of Denmark: Electric Power Engineering Department, report no 8107, 1981.

[4] Mamdani, E.H.: "Application of Fuzzy Logic to Approximate Reasoning". IEEE Trans Computers. $1977, \mathrm{c}-26(12), 1182$ - 1191 .

[5] Pedrycz, W.: "Fuzzy Control and Fuzzy Systems". New York and Toronto: Wiley, 1989.

[6] Tang, K.L. \& R.J. Mulholland: "Comparing. Fuzzy Logic with Classical Controller Designs". IEEE Trans on Systems. Man. and Cybernetics, 1987, SMC-17(6), 1085-1087.

[7] Smith. L.C.: "Fundamentals of Control Theory". Chemical Engineering, Deskbook Issue, 1979, 86 (22), 11-39.

[8] Yamazaki, T.: "An Improved Algorithm for a SelfOrganising Controller, and its Experimental Analvsis." Queen Mary College, London: Dept. of Electrical and Electronic Engineering, 1982 (Ph.D. thesis).

[9] Zadeh, L.: "Outline of a new Approach to the Analysis of Complex Systems and Decision Processes." IEEE Trans Smc. $1973,3,28-44$.

\section{APPENDIX: Analogies between PID and fuzzy controllers}

This appendix establishes the mathematical relationships between fuzzy and PID (proportional-integral-derivative) controllers.

A discrete version of a PID controller can be written

$O(n)=K p *\left[e(n)+(1 / T i)^{n} \Sigma e_{j} * T s+T d *(e(n)-e(n-1)) / T s\right]$ 
where $O$ is the controller output, index $\mathrm{n}$ is the time instant, $\mathrm{Kp}$ is the proportional gain, and e is the setpoint error. The $\mathrm{Ti}, \mathrm{Td}$ and $\mathrm{Ts}$ are integral, derivative and sampling time respectively.

The fuzzy CO-controller produces an incremental change in output, $\mathrm{CO}$, which is a function $\mathrm{F}$ of the inputs to the controller (Fig. 1)

$\mathrm{CO}(\mathrm{n})=\mathrm{GCO} * \mathrm{~F}(\mathrm{E}(\mathrm{n}), \mathrm{CE}(\mathrm{n}))$

The function $F$ includes clipping, quantization and a lookup in a table. Replacing $F$ by a summation, one can turn eq: (2) into a form similar to eq. (1)

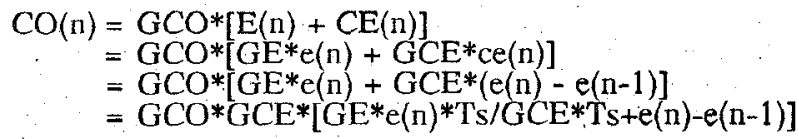

Integrating the left hand side and the right hand side provides

$\mathrm{O}(\mathrm{n})=\mathrm{GCO} * G C E *[(G E /(G C E * T s)) * \Sigma e(j) * T s+e(n)]$

Comparing terms in eqs. (1) and (4), it is clear that $\mathrm{GCO}^{*} \mathrm{GCE}$ is equivalent to $\mathrm{Kp}$, and GE/(GCE*Ts) is equivalent to $1 / \mathrm{Ti}$. Consequently, the fuzzy CO-controller is similar to a PI controller.

The fuzzy O-controller produces a control signal, also as a result of a function $F$

$\mathrm{O}(\mathrm{n})=\mathrm{GO} * \mathrm{~F}[\mathrm{E}(\mathrm{n}), \mathrm{CE}(\mathrm{n})]$

Replacing $\mathrm{F}$ by summation again, yields

$$
\begin{aligned}
\mathrm{O}(\mathrm{n}) & =G \mathrm{G}^{*}[\mathrm{E}(\mathrm{n})+\mathrm{CE}(\mathrm{n})] \\
& =\mathrm{GO}^{*}\left[\mathrm{GE} * \mathrm{e}(\mathrm{n})+\mathrm{GCE}^{*} \mathrm{ce}(\mathrm{n})\right] \\
& =\mathrm{GE}^{*} \mathrm{GO}^{*}\left[\mathrm{e}(\mathrm{n})+(\mathrm{GCE} / \mathrm{GE})^{*} \mathrm{ce}(\mathrm{n})\right] \\
& =\mathrm{GE}^{*} \mathrm{GO}^{*}\left[\mathrm{e}(\mathrm{n})+\left(G C \mathrm{G}^{*} \mathrm{Ts} / \mathrm{GE}\right)^{*}(\mathrm{e}(\mathrm{n})-\mathrm{e}(\mathrm{n}-1)) / \mathrm{Ts}\right]
\end{aligned}
$$

Comparing terms with eq. (1), one sees that $\mathrm{GE}^{*} \mathrm{GO}$ is equivalent to $\mathrm{Kp}$, and GCE*Ts/GE is equivalent to Td, i.e. the fuzzy $\mathrm{O}$-controller is similar to a $\mathrm{PD}$ controller.

To get a fuzzy controller similar to a PID controller, one could add a third input, integral error IE, to the $\mathrm{O}$-controller configuration. If we define

$$
\begin{aligned}
& \mathrm{IE}(\mathrm{n})=\operatorname{GIE} * \mathrm{ie}(\mathrm{n})=\mathrm{GIE}^{*}{ }_{0}^{{ }^{\mathrm{n}} \mathrm{e}^{*} \mathrm{Ts}}, \\
& \operatorname{ce}(\mathrm{n})=(\mathrm{e}(\mathrm{n})-\mathrm{e}(\mathrm{n}-1)) / \mathrm{Ts}
\end{aligned}
$$

the fuzzy PID controller is,

$\mathrm{O}(\mathrm{n})=\mathrm{GO} * \mathrm{~F}[\mathrm{E}(\mathrm{n}), \mathrm{CE}(\mathrm{n}), \mathrm{IE}(\mathrm{n})]$

The function $F$ includes a lookup in a three-dimensional table.

Replacing $\mathrm{F}$ by summation yields

$\mathrm{O}(\mathrm{n})=$

$\mathrm{GO} *[\mathrm{E}(\mathrm{n})+\mathrm{CE}(\mathrm{n})+\mathrm{IE}(\mathrm{n})]=$

$\mathrm{GQ}^{*}[\mathrm{GE} * \mathrm{e}(\mathrm{n})+\mathrm{GCE} * \mathrm{ce}(\mathrm{n})+\mathrm{GIE} * \mathrm{ie}(\mathrm{n})]=$
$\mathrm{GO}^{*}\left[\mathrm{GE}^{*} \mathrm{e}(\mathrm{n})+\mathrm{GCE}(\mathrm{e}(\mathrm{n})-\mathrm{e}(\mathrm{n}-1)) / \mathrm{Ts}+\mathrm{GIE}^{*} \Sigma_{0}^{\mathrm{n}} \mathrm{e}^{*} \mathrm{Ts}\right]=$
$\mathrm{GO}^{*} \mathrm{GE} *\left[\mathrm{e}(\mathrm{n})+\mathrm{GIE} / \mathrm{GE}^{*} \Sigma \mathrm{e}^{*} \mathrm{Ts}+\mathrm{GCE} / \mathrm{GE}^{*}(\mathrm{e}(\mathrm{n})-\mathrm{e}(\mathrm{n}-1)) / \mathrm{Ts}\right]$
0

Comparing terms with eq. (1), one sees that GO*GE is equivalent to $\mathrm{Kp}, \mathrm{GIE} / \mathrm{GE}$ is equivalent to $1 / \mathrm{Ti}$, and GCE/GE is equivalent to Td, i.e. a PID controller. 